\title{
Longitudinal Growth During Infancy and Childhood in Children from Shanghai: Predictors and Consequences of the Age at Onset of the Childhood Phase of Growth
}

\author{
XIU XU, WEIPING WANG, ZHIPING GUO, AND JOHAN KARLBERG \\ Department of Child Health Care, Children's Hospital of Fudan University, Shanghai 200032, P.R. China \\ [X.X., W.P.W., Z.P.G.]; Department of Paediatrics [X.X., J.K.]; and Clinical Trials Centre, Faculty of \\ Medicine [J.K.], The University of Hong Kong, Hong Kong SAR, P.R. China
}

\begin{abstract}
ABS
The age at onset of the childhood phase of growth, normally
occurring between 6 and $12 \mathrm{mo}$, is recognized to be an important
time during postnatal human development. The aims of this
present work were to identify predictors for the age at onset of
the childhood phase of growth. Furthermore, this work aimed to
examine the consequences that this timing would have on the
subsequent heights of 1720 Shanghai children. The mean age of
the infants at onset of the childhood phase of growth was 11.2 mo
in boys and 10.7 mo in girls. Compared with their Swedish
counterparts, these means occurred 1.3 mo later in boys and 1.4
mo later in girls. Both age at onset of the childhood phase of
growth and length at 6 mo of age significantly ( $p<0.05)$
contributed to the attained height from 12 mo of age onward;
1-mo delay in the onset of the childhood phase of growth reduced
height at 5 y of age by $0.4 \mathrm{~cm}$ in boys and $0.5 \mathrm{~cm}$ in girls. The
\end{abstract}
age at onset of the childhood phase of growth was negatively associated $(p<0.001)$ with mid-parental height, although positively related $(p<0.001)$ to height at 6 mo of age. There was a distinct body mass index pattern of Chinese children between birth and 6 y of age in comparison with white values. There was a sharp increase in body mass index in Shanghainese during their first 6 mo of life, followed by a gradual decline up to $24 \mathrm{mo}$. In conclusion, the age at childhood onset is equally important when studying children from Shanghai as it is with their Swedish counterparts. (Pediatr Res 51: 377-385, 2002)
Abbreviations
ICP, infancy-childhood-puberty
BMI, body mass index

The ICP growth model divides human growth into three successive and partly superimposed phases-infancy, childhood, and puberty - reflecting the endocrinology of the growth process $(1,2)$. The infancy phase of the ICP model has been assumed to begin mid-gestation and tails off at approximately 3-4 y of age, representing the postnatal extension of fetal growth; it is regarded as being nutrition dependent, closely linked to the action of IGFs $(3,4)$. The second phasechildhood-starts during the second half-year of life and slowly decelerates, although it continues into puberty until growth ceases. This phase has been taken to mirror the effect of GH $(5,6)$. The normal range for the age at onset of the childhood phase of growth had previously been depicted to

Received November 9, 2000; accepted June 18, 2001

Correspondence and reprint requests: Johan Karlberg, M.D., Clinical Trials Centre, The University of Hong Kong, Hong Kong SAR, P.R. China; e-mail: jpekarl@hkucc.hku.hk Supported by the Children's Hospital of Fudan University, Shanghai, PR China, the Clinical Trials Centre, and the Department of Paediatrics and the Faculty of Medicine, The University of Hong Kong, Hong Kong SAR, PR China. occur between 6 and 12 mo (7) and more recently, based on a larger set of data, between 6 and 15 mo of age (8).

A delay in the age at onset of the childhood phase of growth generally accounts for a significant portion of the growth deficit in those observed (9). In a recent work, it has also been shown that the age at onset of the childhood phase of growth has a lifelong impact; 1 mo later than average will reduce final height by $0.5 \mathrm{~cm}$. So far, the following predictors have been identified for the age at onset of the childhood phase of growth: sex (7), various diseases (2), socioeconomic factors $(9,10)$, length/growth velocity before onset (7), and IGF-I serum level (11).

The aims of this study were to identify any new predictors for the age at onset of the childhood phase of growth and the consequences of this timing on subsequent heights in 1720 longitudinally monitored Shanghai children. Then these results were compared with the results obtained from previous longitudinal studies.

\section{METHODS}

The data series represents a community-based, longitudinal, child-health monitoring system carried out at the Department 
of Child Health Care, Children's Hospital of Fudan University, PR China. The study population consisted of 6018 full-term children, born between January 1, 1980, and December 31, 1990, i.e. 11 birth-year cohorts, in Fenglin Community, Shanghai; 3202 boys (53.2\%) and 2816 girls (46.8\%).

Exactly 1720 children remained for continual monitoring at the clinic at 6 y of age, representing $28.6 \%$ of the total sample. To estimate ages at onset of the childhood phase of the ICP growth model, at least three repeated length measurements are needed at approximately $1 \mathrm{y}$ of age (7); 97 subjects did not fulfill this criterion and they were therefore deleted from the analysis. As a result, 1623 children remained in the analysis, i.e. 849 boys and 774 girls.

\section{Socioeconomic Status}

The educational levels that were achieved by the parents were reported to the clinic upon their first visit. Education levels were categorized into three sections, namely primary, secondary, and postsecondary.

\section{Body Measurements}

The children were routinely monitored in the department up to the age of $6 \mathrm{y}$. They were measured approximately monthly from birth to 6 mo of age, then every 3 mo from 6 to $12 \mathrm{mo}$, every 6 mo from 12 to $36 \mathrm{mo}$, and annually from 3 to 6 y of age. Measurements taken $3 \mathrm{~d}$ before or after the children's exact monthly ages, during their first 6 mo of life, were kept. Similarly, measurements taken $7 \mathrm{~d}$ before or after the children's exact monthly ages, during the second half-year, were also kept. Between the ages of 1 and $3 \mathrm{y}$, an acceptable margin of up to $14 \mathrm{~d}$, before or after the children's exact yearly ages, was allowed. The margin for children aged between 4 and $6 \mathrm{y}$ was increased to 1 mo before or after the children's exact yearly ages. Records that did not meet these criteria were not included in the analysis.

Weight. Children $<3$ y of age were weighed on a balancebeam scale. Beginning from the age of $3 \mathrm{y}$, children were weighed on a standing-beam scale. Their weight was measured to the nearest $50 \mathrm{~g}$.

Length/height. For children $<3$ y of age, height was measured as supine length. From the age of 3 y onward, the children's standing height was measured using a stadiometer attached to a wall. Both length and height were measured to the nearest $0.1 \mathrm{~cm}$.

Body mass index. The individual BMI was calculated as weight/length ${ }^{2}\left(\mathrm{~kg} / \mathrm{m}^{2}\right)$.

Growth velocity. Growth velocities for weight, length/ height, and BMI were defined as the increment in body size in $\mathrm{kg}, \mathrm{cm}$, and $\mathrm{kg} / \mathrm{m}^{2}$ during age periods of 3-6 mo, 12-36 mo, and 36-72 mo of age.

Parental weight and height. Parental weight and height were also measured at the Department of Health Care at their first visit to the clinic. Weight was measured to the nearest $50 \mathrm{~g}$ and height to the nearest $0.1 \mathrm{~cm}$.

\section{Determination of Age at Onset of the Childhood Phase of Growth}

The age at onset of the childhood phase of growth was determined individually, in units of $1 \mathrm{mo}$, by visual inspection of the data contained within the individual computergenerated, ICP-based growth chart for both length and length velocity (Fig. 1) (7). The age at onset of the childhood phase of growth was identified visually from this chart and was defined as an abrupt increase in growth velocity, in line with previous reports $(7,10,12)$. Using this methodology, the age at onset of the childhood phase of growth was determined in 1623 individual children ( 849 boys, 774 girls). The age at onset of the childhood phase of growth was determined in all children by one of the authors (X.X.). However, the first 200 growth charts were also reviewed by another author (J.K.), who also concurred with our findings. The interobserver error was 3.5\%.

The mean weight, length, and BMI values were all compared against a set of recent Swedish growth reference values (13, 14). These reference values were chosen because they are based on the same methodology as the analysis of the age at onset of the childhood phase of growth in Shanghai children.

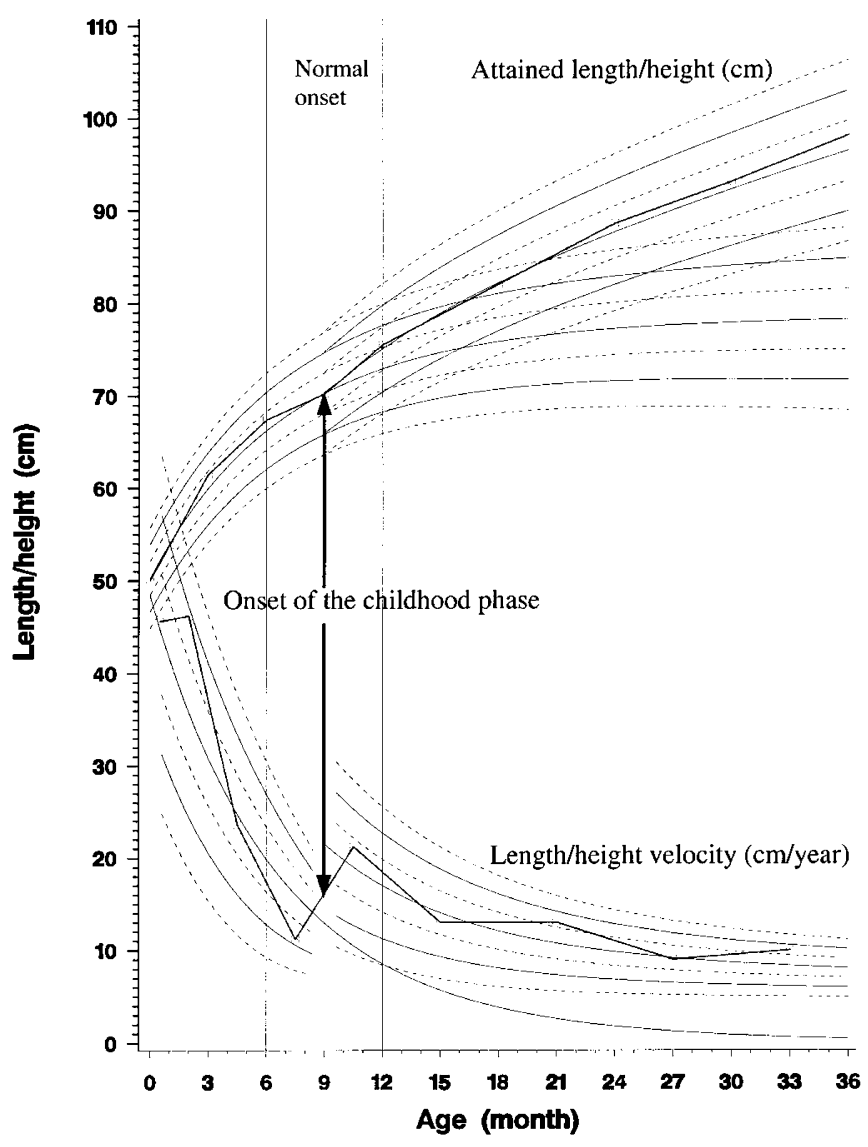

Figure 1. Computer-generated ICP growth chart with themean curve and 3 SD curves about the mean for the infancy phase and the combined growth (infancy + childhood) for both attained length and length velocity (7). The original longitudinal data were plotted individually on this chart to facilitate the determination of ages at the onset of the childhood phase of growth. The age at onset was identified visually as an abrupt increase in length growth velocity and its corresponding change in the attained length growth pattern. Two vertical reference lines indicate the approximate normal range of the age of onset of the childhood phase of growth $(7,8)$. 


\section{Statistical Analysis}

Both $t$ tests and $\chi^{2}$ tests were used for the comparisons of background measurements, between both the included and excluded children and also the distribution of the age at onset of the childhood phase of growth between Shanghai children and Swedish children. Multiple linear regression analyses were used to describe, first, the variation in length/height at various ages; second, the variation of the age at childhood onset; and third, the variation in growth velocities at various age intervals. All analyses and graphics were prepared using SAS software, version $6.10(15)$.

\section{RESULTS}

There was no significant difference $(p>0.05)$ in background measurements, such as sex, educational level, body size at $1 \mathrm{mo}$, and parental height between the children monitored for $<6 \mathrm{y}$ and the children monitored for $6 \mathrm{y}$ of age, as well as between the included $(n=1623)$ and excluded children $(n=$ 97).

Figure 2 illustrates the mean weight, length/height, and BMI values for boys in the 11 birth groups from birth to $6 \mathrm{y}$ of age, together with Swedish growth reference curves. The mean length/height values of Shanghai children were similar to the Swedish mean values during the first year of life. Then they gradually fell below the Swedish mean values to reach a position of approximately $0.5 \mathrm{SD}$ below the mean at $2 \mathrm{y}$ of age, where they remained at this level until $36 \mathrm{mo}$. However, from 36 mo of age onward, the Shanghai mean values increased to reach the Swedish mean values at 6 y of age.

A similar pattern was seen regarding weight. In contrast to the Swedish values, the mean Shanghai BMI increased during the first 3 mo of life, reaching a peak maximum difference at around 9 mo, followed by a gradual decline to approximately $25 \%$ of the Swedish value from 12 to 24 mo. The mean BMI values gradually increased from 36 mo and stabilized between $25 \%$ and $50 \%$ of the Swedish reference. These age-dependent growth patterns are further highlighted in Figure 3 in terms of the mean difference from the Swedish mean reference values. Note that some constant differences can be noted for the various birth-year groups. A same phenomenon has been seen in girls (details not given in figure).

Table 1 compares the distribution of the age at onset of the childhood phase of growth between Shanghai children and Swedish children (10). There was a significant $(p<0.05)$ difference in the distribution of the age at onset of the childhood phase of growth between the Shanghai and Swedish populations. The mean \pm SD of the age onset of the childhood phase of growth among the Shanghai series was $11.5 \pm 2.67$ mo for boys, and $10.9 \pm 2.20$ mo for girls, but with a significant $(p<0.05)$ unevenness in the distribution. A natural logarithmic transformation was applied to the data, which gave a mean value of 2.41 (the antilog mean value was $11.2 \mathrm{mo}$ ) and an SD value of 0.233 mo for boys, and a mean of 2.37 (the antilog mean value was $10.7 \mathrm{mo}$ ) and an SD value of $0.202 \mathrm{mo}$ for girls. The antilog mean age at onset of the childhood phase of growth value was 1.3 mo later for boys and 1.4 mo later for girls than their Swedish counterparts. The age at onset of the
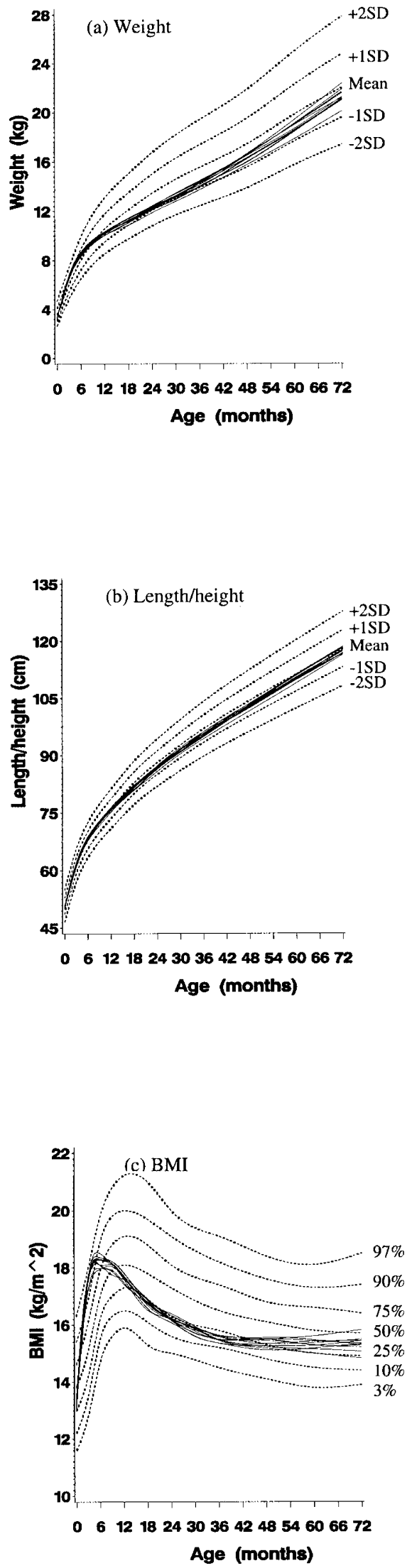

Figure 2. Mean weight, length, and BMI for boys in the 11 birth groups (solid lines) monitored up to $6 \mathrm{y}$ of age at the Children's Hospital of Shanghai Medical University. The new Swedish growth reference values (dashed lines) are included here for comparison $(13,14)$. 
childhood phase of growth in girls occurred significantly $\left(\chi^{2}\right.$ test, $p<0.05)$ earlier than it did in boys in Shanghai populations; there was, however, no significant $\left(\chi^{2}\right.$ test, $\left.p>0.05\right)$ difference in the distribution of age at onset of the childhood phase of growth during the 11 birth-years for either boys or girls in Shanghai (results not given).

Figure 4 illustrated the relationship between the age at onset of the childhood phase of growth and body length as well as length velocity. The mean values of length/height among the four groups were found to be significantly $(p<0.05)$ different from 12 mo onward. At 72 mo of age, the mean difference between the earliest age at onset of the childhood phase of growth group and the latest one was about $5 \mathrm{~cm}$. However, a significant $(p<0.05)$ difference in the mean length/height velocities among the four groups were in principle only found during the following intervals: $3-6,6-9,9-12$, and $12-18$ mo of age. Note that the mean velocity values were inversely related to age at onset of the childhood phase of growth at 3-6 mo of age.

In Figure 5, the BMI velocity values showed consistently significant $(p<0.05)$ differences between groups of the age at onset of the childhood phase of growth during the transition period from infancy to childhood phase of growth. The mean BMI velocity values were higher for the earlier group of the age at onset of the childhood phase of growth than they were for the later ones (before the age at onset of the childhood phase of growth, i.e. 3-6 mo of age). This is contrary to the observation found for length velocity at this age interval (Fig. 4). Girls have the same results as boys (details not given).

A multiple regression model, with length at 6 mo of age and the age at onset of the childhood phase of growth as independent variables, was applied to the series (Table 2). Both length at 6 mo of age and the age at onset of the childhood phase of growth were significantly $(p<0.05)$ related to length/height from 12 mo of age onward for both sexes. The total $R^{2}$ was between 0.45 and 0.74 . The importance of the age at onset of the childhood phase of growth for height at $5 \mathrm{y}$ of age in Shanghai children was similar to that in their Swedish counterparts; i.e. 1-mo delay in the age at onset of the childhood phase of growth was associated with a reduction in height by approximately $0.4 \mathrm{~cm}$ for boys and $0.5 \mathrm{~cm}$ for girls (Table 2).

Table 3 gives the multiple linear regression analyses of influential factors on the age at onset of the childhood phase of growth. The age at onset of the childhood phase of growth was found to be significantly $(p<0.05)$ associated with the sex of the child, length at 6 mo of age, and mid-parental height. A simple linear regression was applied to the age at onset of the childhood phase of growth and mid-parental height (Fig. 6); the slope $(\beta)$ was -0.076 in boys and -0.067 in girls, which means that the age at onset of the childhood phase of growth was 1.5 mo later in boys and 1.3 mo later in girls, for children with a mid-parental height -2 SD below the mean in comparison with the children of tall parents, i.e. a mid-parental height equal to mean $+2 \mathrm{SD}$.

In line with the noted difference in the growth pattern before and after 36 mo of age (Fig. 3), we divided the period between 12 to $72 \mathrm{mo}$ of age into two age intervals, i.e. $12-36 \mathrm{mo}$ and 36-72 mo. A multiple linear regression analysis was applied to
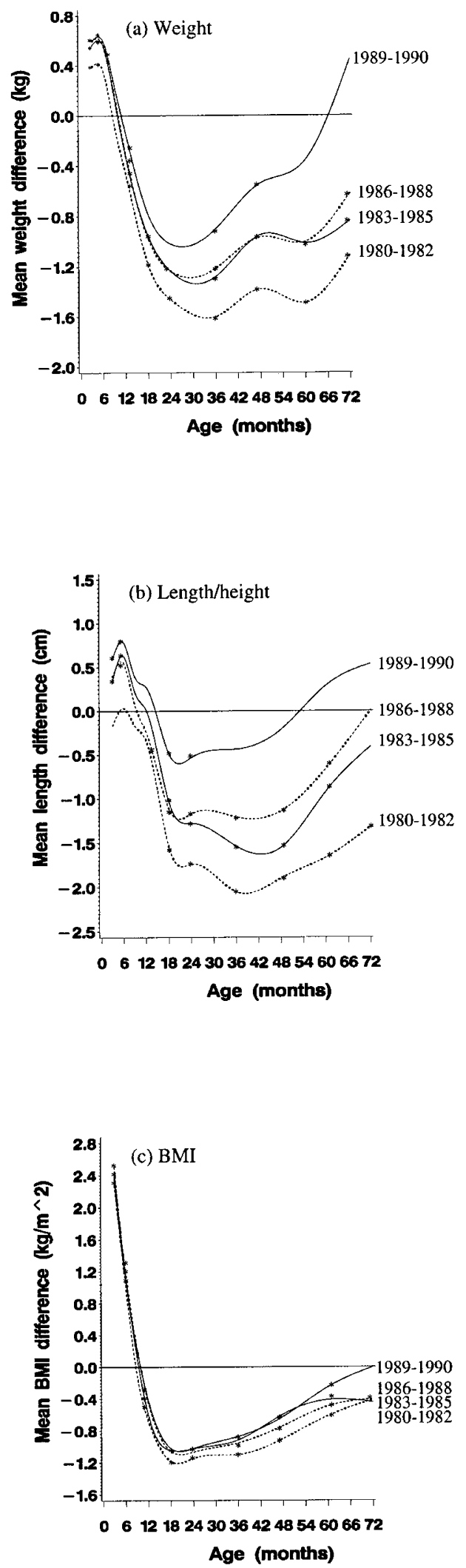

Figure 3. The mean difference for three body measurements - weight, length, and BMI-between the individual Shanghai boys measurements and the Swedish mean values with a zero line of unity. The Shanghai data were separated into four groups by year of birth: 1980-1982, 1983-1985, 19861988, and 1989-1990. A $t$ test with an expected mean value of zero was applied to each age and birth-year group values. Significant $(p<0.05, t$ test with an expected value of zero) differences are indicateded $(*)$. 
Table 1. Distribution of age at onset of childhood phase of growth between Shanghai children and Swedish children

\begin{tabular}{|c|c|c|c|c|c|c|c|}
\hline \multirow[b]{2}{*}{ Sex } & \multirow[b]{2}{*}{$\begin{array}{l}\text { Childhood onset } \\
\text { (mo) }\end{array}$} & \multicolumn{3}{|c|}{ Shanghai children $(n=1623)$} & \multicolumn{3}{|c|}{ Swedish children $(n=2422)$} \\
\hline & & $\begin{array}{c}\text { Frequency } \\
n\end{array}$ & $\begin{array}{c}\text { Percent } \\
\%\end{array}$ & $\begin{array}{l}\text { Cumulative } \\
\text { percent } \%\end{array}$ & $\begin{array}{c}\text { Frequency } \\
n\end{array}$ & $\begin{array}{c}\text { Percent } \\
\%\end{array}$ & $\begin{array}{c}\text { Cumulative } \\
\text { percent } \%\end{array}$ \\
\hline \multirow{3}{*}{ Boys* } & $9.0-11.9$ & 314 & 37.0 & 43.4 & 644 & 53.3 & 76.6 \\
\hline & $12.0-14.9$ & 371 & 43.7 & 87.1 & 236 & 19.5 & 96.1 \\
\hline & $15.0-17.9$ & 74 & 8.7 & 95.8 & 34 & 2.8 & 98.9 \\
\hline \multirow{4}{*}{ Girlst: } & $9.0-11.9$ & 338 & 43.7 & 49.5 & 655 & 54.0 & 86.0 \\
\hline & $12.0-14.9$ & 333 & 43.0 & 92.5 & 140 & 11.5 & 97.5 \\
\hline & $15.0-17.9$ & 50 & 6.5 & 99.0 & 22 & 1.8 & 99.3 \\
\hline & $18.0+$ & 8 & 1.0 & 100.0 & 9 & 0.7 & 100.0 \\
\hline
\end{tabular}

* Boys: Shanghai vs Swedish; $\chi^{2}=268.7, p<0.0001$.

$\dagger$ Girls: Shanghai $v$ S Swedish; $\chi^{2}=384.0, p<0.0001$.

$\ddagger$ Shanghai: boys $v$ s girls; $\chi^{2}=22.8, p<0.0001$.

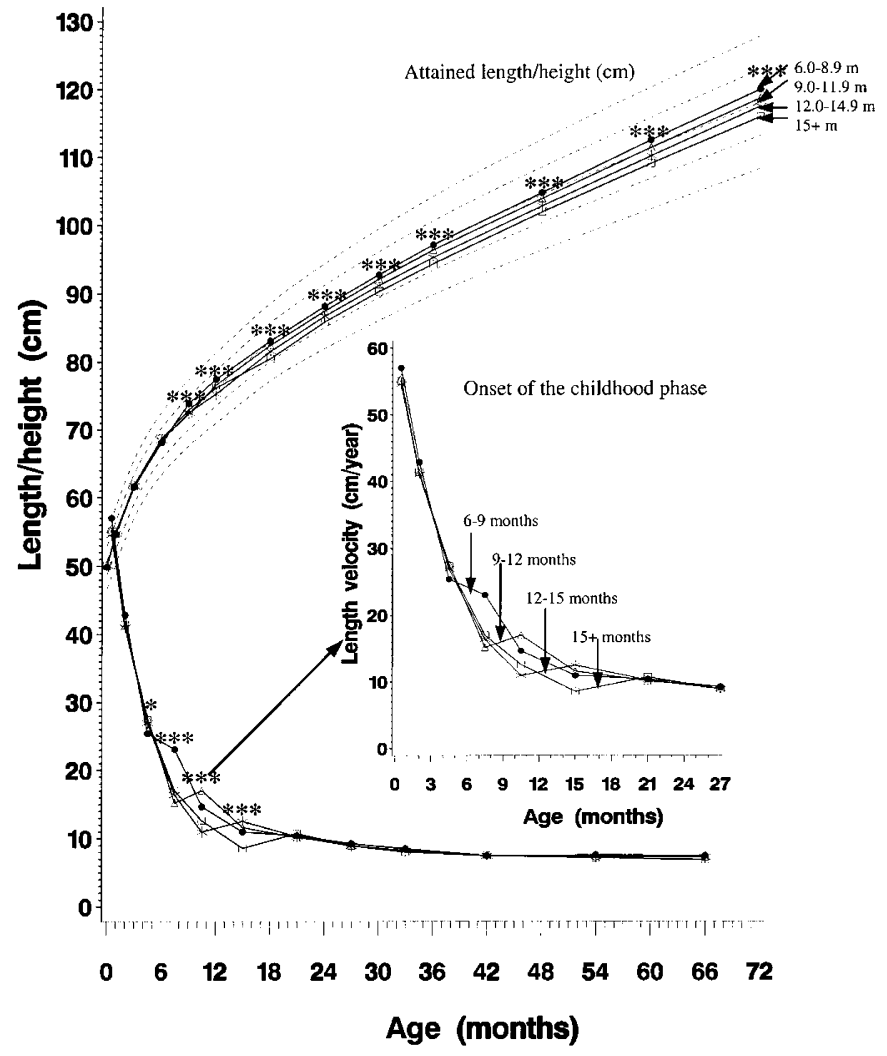

Figure 4. Mean attained length and mean length velocity for boys in four groups of the age at childhood phase of growth; the age at onset between 6.0 and 8.9 mo of age (circles, $n=54), 9.0-11.9$ mo (triangles, $n=314$ ), $12-14.9$ mo (stars, $n=371$ ), and $\geq 15$ mo (squares, $n=110$ ). The new Swedish growth reference values are also given here (14). The Kruskal-Wallis k-sample test was applied to any differences in the central tendency of attained length and length velocity among the four groups; ${ }^{*} p<0.05,{ }^{* *} p<0.01$, and ${ }^{* * *} p$ $<0.0001$.

the series to explain the variation in height gain during these two age intervals (Table 4 ). The height gain at $12-36$ mo of age was found to be significantly $(p<0.05)$ related to the age at onset of the childhood phase of growth, birth year, sex, BMI at 12 mo of age, mid-parental height, and mid-parental BMI at birth. The height gain at 36-72 mo of age was also found to be significantly $(p<0.05)$ associated to birth year, sex, height and

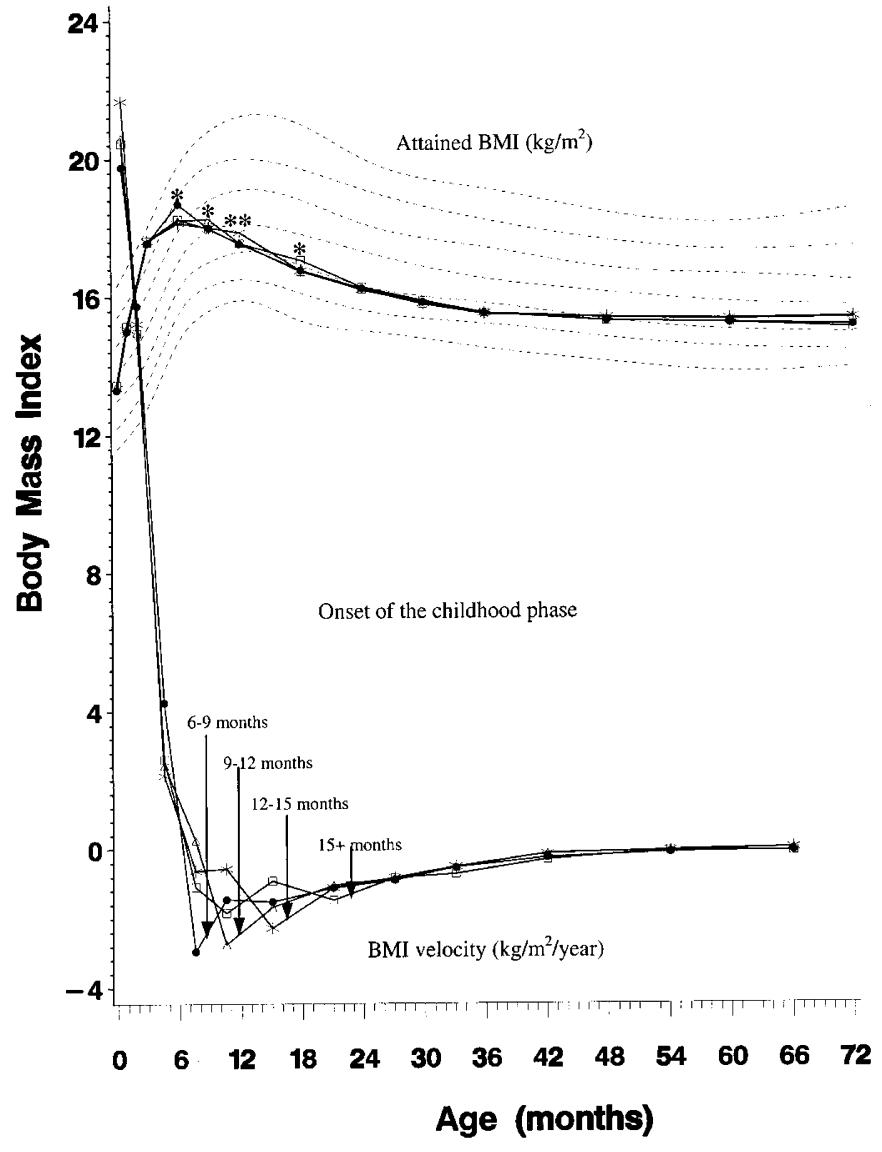

Figure 5. Mean BMI and mean BMI velocity for boys in four groups of the age at childhood phase of growth; the age at onset between 6.0 and 8.9 mo of age (circles, $n=54$ ), 9.0-11.9 mo (triangles, $n=314$ ), 12-14.9 mo (stars, $n$ $=371$ ), and $\geq 15$ mo (squares, $n=110$ ). The new Swedish growth reference values are also given (13). The Kruskal-Wallis k-sample test was applied to any differences in the central tendency of attained BMI and BMI velocity among the four groups; ${ }^{*} p<0.05,{ }^{* *} p<0.01$, and ${ }^{* * *} p<0.0001$.

BMI at 36 mo of age, BMI gain at both $12-36$ mo of age and at 36-72 mo, and mid-parental height. Note that the age at onset of the childhood phase of growth was not found to offer a satisfactory explanation $(p>0.05)$ for variations in height gain at $36-72$ mo of age. 
Table 2. Impact of age at onset of childhood phase of growth (in months) on linear growth at various ages analyzed by a multiple linear regression model* with adjustment for the height $(\mathrm{cm})$ at 6 mo of age

\begin{tabular}{|c|c|c|c|c|c|c|c|c|c|}
\hline & & & & & & \multicolumn{4}{|c|}{ Slope } \\
\hline & & & & \multicolumn{2}{|c|}{ Intercept } & \multicolumn{2}{|c|}{ Length at $6 \mathrm{mo}$} & \multicolumn{2}{|c|}{ Childhood onset } \\
\hline \multicolumn{2}{|c|}{ Age (mo) } & Sex & $R^{2}$ & $\alpha$ & $p$ & $\beta_{1}$ & $p$ & $\beta_{2}$ & $p$ \\
\hline \multirow[t]{18}{*}{ Shanghai } & 0 & Boys & 0.0004 & 50.27 & 0.0001 & & & -0.01 & 0.75 \\
\hline & & Girls & 0.0039 & 50.26 & 0.0001 & & & -0.04 & 0.29 \\
\hline & 6 & Boys & 0.0010 & 68.21 & 0.0001 & & & 0.02 & 0.37 \\
\hline & & Girls & 0.0015 & 66.37 & 0.0001 & & & 0.04 & 0.28 \\
\hline & 12 & Boys & 0.73 & 11.54 & 0.0001 & 0.97 & 0.0001 & -0.18 & 0.0001 \\
\hline & & Girls & 0.74 & 15.78 & 0.0001 & 0.92 & 0.0001 & -0.26 & 0.0001 \\
\hline & 18 & Boys & 0.71 & 15.27 & 0.0001 & 1.02 & 0.0001 & -0.31 & 0.0001 \\
\hline & & Girls & 0.69 & 18.21 & 0.0001 & 0.99 & 0.0001 & -0.33 & 0.0001 \\
\hline & 24 & Boys & 0.63 & 17.00 & 0.0001 & 1.07 & 0.0001 & -0.28 & 0.0001 \\
\hline & & Girls & 0.62 & 18.79 & 0.0001 & 1.06 & 0.0001 & -0.34 & 0.0001 \\
\hline & 36 & Boys & 0.60 & 18.79 & 0.0001 & 1.18 & 0.0001 & -0.34 & 0.0001 \\
\hline & & Girls & 0.60 & 19.80 & 0.0001 & 1.19 & 0.0001 & -0.45 & 0.0001 \\
\hline & 48 & Boys & 0.57 & 19.66 & 0.0001 & 1.28 & 0.0001 & -0.35 & 0.0001 \\
\hline & & Girls & 0.55 & 22.35 & 0.0001 & 1.28 & 0.0001 & -0.48 & 0.0001 \\
\hline & 60 & Boys & 0.51 & 22.38 & 0.0001 & 1.35 & 0.0001 & -0.40 & 0.0001 \\
\hline & & Girls & 0.52 & 22.02 & 0.0001 & 1.41 & 0.0001 & -0.56 & 0.0001 \\
\hline & 72 & Boys & 0.46 & 25.40 & 0.0001 & 1.43 & 0.0001 & -0.46 & 0.0001 \\
\hline & & Girls & 0.47 & 23.50 & 0.0001 & 1.50 & 0.0001 & -0.63 & 0.0001 \\
\hline \multirow[t]{2}{*}{ Swedish $\dagger$} & 60 & Boys & 0.24 & 40.00 & 0.0001 & 1.10 & 0.0001 & -0.40 & 0.0001 \\
\hline & & Girls & 0.37 & 27.60 & 0.0001 & 1.32 & 0.0001 & -0.49 & 0.0001 \\
\hline
\end{tabular}

* Function: Height $=\alpha+\beta_{1} \times$ length at 6 mo $+\beta_{2} \times$ childhood onset.

$\dagger$ Taken from Pediatr Res 2000;47:475-480.

Table 3. Multiple linear regression model $\left(\mathrm{R}^{2}=0.04\right)$ with age at onset of childhood phase of growth (in months) in Shanghai children as the dependent variable $(\mathrm{n}=1455)$

\begin{tabular}{lcl}
\hline \multicolumn{1}{c}{ Characteristic } & $\beta$ & \multicolumn{1}{c}{$p$} \\
\hline Intercept & 21.03 & 0.0001 \\
Birth-year groups* & -0.04 & 0.59 \\
Sex (boy = 1, girl = 2) & -0.33 & 0.03 \\
Length at 6 mo & 0.14 & 0.0003 \\
BMI at 6 mo & -0.02 & 0.72 \\
Length gain at 3-6 mo & -0.01 & 0.32 \\
BMI gain at 3-6 mo & -0.03 & 0.19 \\
Mid-parental height $(\mathrm{cm})$ & -0.10 & 0.0001 \\
Mid-parental BMI $\left(\mathrm{kg} / \mathrm{m}^{2}\right)$ & -0.07 & 0.06 \\
\hline
\end{tabular}

* Birth-year groups: $1980-1982=1 ; 1983-1985=2 ; 1986-1988=3$; $1989-1990=4$.

\section{DISCUSSION}

In this study we have applied the ICP growth model to a large series of longitudinal growth data from Shanghai. The analysis confirmed that previous findings related to the importance of the age at onset of the childhood phase of growth on subsequent height are also valid for the Chinese population under study. The novel findings of this work are 1) a strong negative association between mid-parental height and the age at onset of the childhood phase of growth, 2) the positive relationship between height at 6 mo of age and the age at onset of the childhood phase of growth, and 3) a distinct BMI pattern of Chinese children between birth and $6 \mathrm{y}$ of age.

Study design. The methodology for determining the age at onset of the childhood phase of growth has been evaluated and discussed in detail in previous studies $(7,10)$. In this study, one of the authors (X.X.) estimated the age at onset of the childhood phase of growth, after an initial training section. The first

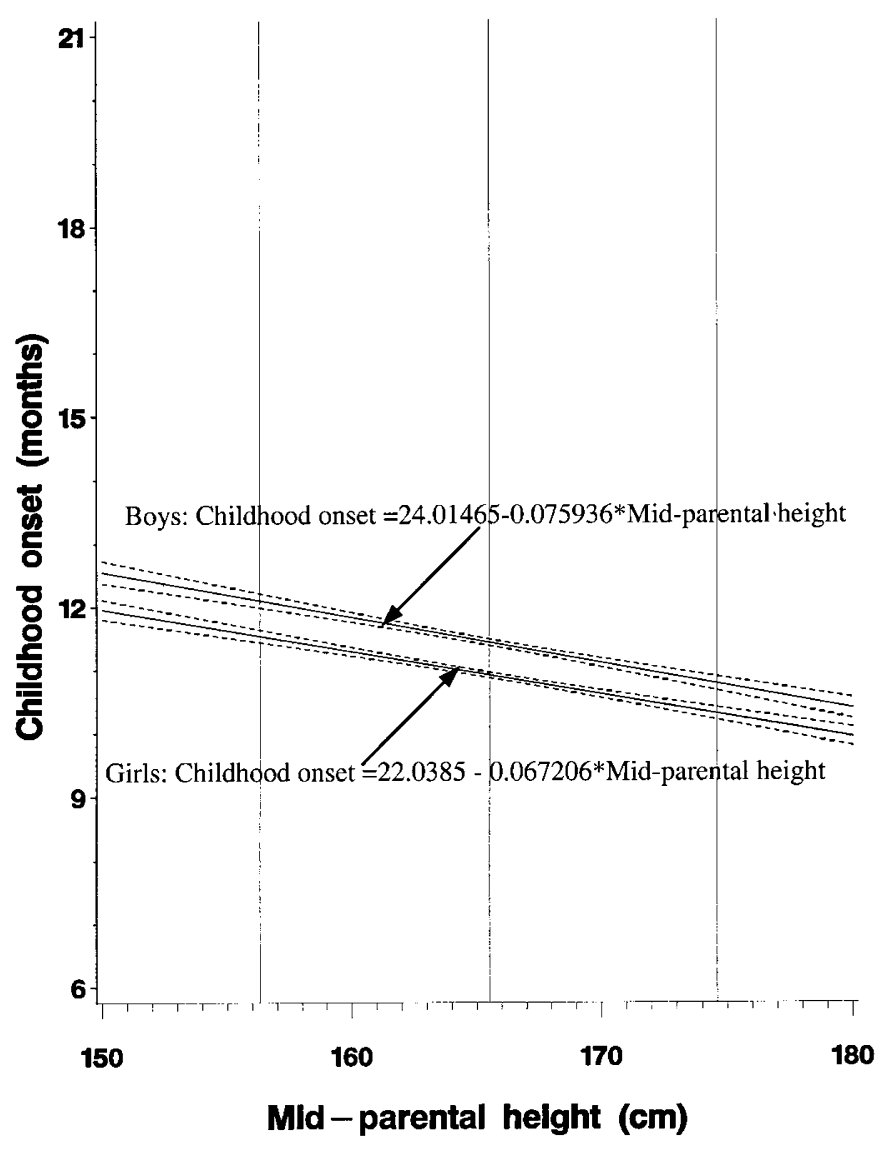

Figure 6. A simple linear regression analysis between the age at onset of the childhood phase of growth (months) and mid-parental height $(\mathrm{cm})$. Boys and girls were treated separately. The vertical lines represent the mean parental height and \pm 2 SD around this mean. The bivariate correlation coefficient was 0.13 for boys and 0.14 for girls. 
Table 4. Multiple linear regression model with the height gain at 12-36 mo of age and the height gain at 36-72 mo in Shanghai children as the dependent variables $(\mathrm{n}=1406)$

\begin{tabular}{|c|c|c|c|c|}
\hline & \multicolumn{2}{|c|}{$\begin{array}{l}\text { Height gain }\left(R^{2}=0.17\right) \text { at } \\
12-36 \mathrm{mo}(\mathrm{cm})\end{array}$} & \multicolumn{2}{|c|}{$\begin{array}{c}\text { Height gain }\left(R^{2}=0.17\right) \text { at } \\
36-72 \mathrm{mo}(\mathrm{cm})\end{array}$} \\
\hline & $\beta$ & $p$ & $\beta$ & $p$ \\
\hline $\begin{array}{l}\text { Age at onset of the childhood phase of } \\
\text { growth (mo) }\end{array}$ & -0.14 & 0.0001 & -0.03 & 0.18 \\
\hline Birth-year groups* & 0.23 & 0.0001 & 0.27 & 0.0001 \\
\hline $\operatorname{Sex}($ boy $=1$, girl $=2)$ & 0.44 & 0.0001 & 0.51 & 0.0001 \\
\hline BMI at start of interval $\left(\mathrm{kg} / \mathrm{m}^{2}\right)$ & 0.03 & 0.60 & 0.16 & 0.02 \\
\hline Weaning age (mo) & 0.02 & 0.07 & 0.00 & 0.78 \\
\hline BMI gain at $12-36 \mathrm{mo}\left(\mathrm{kg} / \mathrm{m}^{2}\right)$ & -0.41 & 0.0001 & 0.37 & 0.0001 \\
\hline BMI gain at $36-72 \mathrm{mo}\left(\mathrm{kg} / \mathrm{m}^{2}\right)$ & \multicolumn{2}{|c|}{ NA } & 0.10 & 0.04 \\
\hline Height gain at $12-36 \mathrm{mo}(\mathrm{cm})$ & \multicolumn{2}{|c|}{ NA } & 0.02 & 0.62 \\
\hline Mid-parental height at child's birth (cm) & 0.10 & 0.0001 & 0.08 & 0.0001 \\
\hline Mid-parental BMI at child's birth $\left(\mathrm{kg} / \mathrm{m}^{2}\right)$ & 0.10 & 0.002 & 0.05 & 0.19 \\
\hline
\end{tabular}

* Birth-year groups: $1980-1982=1 ; 1983-1985=2 ; 1986-1988=3 ; 1989-1990=4$.

200 growth charts were also reviewed by one of the other authors (J.K.), with a high level of agreement. For these reasons, we believe that the age at onset of the childhood phase of growth has been accurately determined in the present study.

Fenglin Community is situated in the southwest of Shanghai, China. The people of the community consist of various educational levels, representing the middle to upper-middle socioeconomic levels of society in Shanghai, China. The growth of children in this community was similar to the Chinese national references for urban children (16). Such a sample should reflect the typical characteristics of the current urban child population in China.

One may argue that the subgroup selected for the present study does not represent the population as a whole. The reason for excluding infants from this study was because of the lack of available longitudinal data, so that the age at onset of the childhood phase of growth could not be determined in an appropriate way or, indeed, its impact on later childhood growth. However, there were no significant differences in the background measurements between the included and excluded children. We feel that the subsample used in this analysis can therefore be taken to represent the population as a whole.

Age at onset of the childhood phase of growth and its consequences. The mean age at onset of the childhood phase of growth (the antilog mean value) was 10.7 mo in girls and 11.2 mo in boys. In two previous Swedish studies, it was reported that girls experienced on average age a 0.6 mo earlier age at onset of the childhood phase of growth than boys did (7, 8 ). There was also a significant difference in the distribution of the age at onset of the childhood phase of growth between the Shanghai and Swedish sample groups. Based on the Swedish normal range of the age at onset of the childhood phase of growth, with an upper limit set to 12 mo of age, we found among the Shanghai children that $23 \%$ of boys and $14 \%$ of girls experienced a delayed childhood onset of growth. This figure was higher than that for the normal Swedish population (approximately 10\%), but not as high as has been reported for various populations with growth-related disorders; for instance, $36.2 \%$ of patients with Turner syndrome, $47.6 \%$ of children with celiac disease, and $69.2 \%$ of children with Sotos syndrome also experience a delay in the age at onset of the childhood phase of growth (2). The Shanghai figure was also much lower than the typical figure for a Pakistani communitybased population, in which nearly half of all children were identified as having a delay in their childhood onset $(9,10)$.

Our finding that there is a close relationship between the age at onset of the childhood phase of growth and early linear growth was also in line with the results of previous studies (10). Up to 6 mo of age, i.e. during the infancy phase, the linear growth was virtually the same across all the different groups of the age at onset of the childhood phase of growth. However, after 6 mo of age, the mean length values among the different groups of the age at onset of the childhood phase of growth diverged significantly. This study showed the importance of age at onset of the childhood phase of growth and length at 6 mo of age, a factor that explained between $45 \%$ and $74 \%$ of variation in length/height from 12 mo of age onward. For each month's delay in the age at onset of the childhood phase of growth, there is a reduction of $0.5 \mathrm{~cm}$ in height at $60 \mathrm{mo}$ of age; this finding is virtually the same as reported for Swedish populations (10).

Predictors of age at onset of childhood phase of growth. Previous studies have reported some predictors for the age at onset of the childhood phase of growth. The most consistently identified predictors are sex, growth-related disorders, and the general socioeconomic status of the population $(2,7,9)$. Another identified predictor of childhood onset age is the magnitude of the infancy phase of growth (7). In this study, we found very much the same predictors - sex, length at 6 mo of age, and a child being shorter than normal during infancy-will, in general, correlate to an earlier onset. However, we have also been able to identify an additional predictor of the age at onset of the childhood phase of growth and that is mid-parental height. This finding implies a genetic influence on the age at onset of the childhood phase of growth so that a child with tall parents will on average have 1-2 mo earlier onset of the childhood phase of growth than a child with short parents (Fig. 6). 
Growth deficit during 12 to 36 mo of age in the Shanghai children. Compared with the Swedish case study, the mean length/height values of Shanghai children were quite similar to the Swedish mean values during the first year of life (Fig. 3). During the second year of life, the mean length values gradually fall below the Swedish mean values to reach a trough at $2 \mathrm{y}$ of age, and they remained at this level for up to $36 \mathrm{mo}$. This age-specific growth pattern in the Shanghai children is remarkably similar to the findings in Hong Kong $(11,17)$, Pakistan (2), and Brazil (18).

The relative reduction in height gain among the Shanghai infants during their second year of life, in comparison with the Swedish infants, can mostly, or at least partly, be explained by the difference in the age at onset of the childhood phase of growth. The age at onset of the childhood phase of growth was also negatively related to height gain between 1 and $3 \mathrm{y}$ of age, after adjusting for significant variables such as birth year, sex, and mid-parental height. We also found an inverse relationship between BMI gain and height gain between 1 and $3 \mathrm{y}$ of age. This observation may simply reflect that children, who are increasing greatly in height during this period, will be large influenced more by the inverse effect of GH (onset of the childhood phase of growth) on adipose tissue $(19,20)$.

A catch-up growth from 3 to $6 y$ of age in Shanghai children. Unexpectedly, the Shanghai children showed a different growth pattern from 36 to 72 mo in comparison with the previous age groups. For all birth-year groups and for both sexes, the mean weight, height, and BMI values increased and reached the mean value (or close to the mean value) of the Swedish reference, especially for the most recent birth groups. However, no relationship was found between the height gain at 36-72 mo of age and either the age at onset of the childhood phase of growth or the height gain at 12-36 mo. This implies that the age at onset of the childhood phase of growth is not associated with the observed catch-up growth between 3 and $6 \mathrm{y}$ of age. To the best of our knowledge, this is the first time catch-up growth, occurring in childhood and based on a community model with noninterventional data, has been observed. The Shanghai children in the 11 birth groups all demonstrated a considerable degree of catch-up growth from 36 to $72 \mathrm{mo}$. To identify the exact reason for this phenomenon, further investigation is needed.

A distinct BMI pattern in Chinese children between birth and $6 y$ of age. Another interesting observation was the different trend in mean BMI between the Shanghai and Swedish children. Compared with their Swedish counterparts, there was a sharp increase in BMI in the Shanghainese during their first 6 mo of life. From approximately 4 to 6 mo, the mean BMI values of the Shanghai children decreased, crossing the median Swedish values at 9 mo of ge and continuing to decline up to 24 mo. It has been shown that the 90th percentile of the BMI values of the Swedish reference are quite similar to that of US national reference between 1 and $7 \mathrm{y}$ of age $(21,22)$. Inasmuch as the US BMI reference values are currently not available before $1 \mathrm{y}$ of age, we opted to use the Swedish values as a reference. Similar BMI patterns have previously been reported for Chinese infants up to $2 \mathrm{y}$ of age; the difference in BMI between normal Chinese and white infants has been speculated to be related to genetic factors during the first year of life and to nutritional factors during the second year (23). However, this observation should be further examined in light of the association between growth and nutrition in early life and cardiovascular risk factor and disease in adulthood. For instance, adult blood pressure has been connected to size at birth (24), changes in BMI in the first year of life (25), and sodium intake in the first year of life (26). In a recent study, based on a cross-section of very lean adult population from China, there was an association between BMI and cardiovascular risk factors previously observed in predominantly overweight Western populations (27); this observation may reflect early life growth and nutrition in the Chinese population.

In conclusion, the age at onset of the childhood phase of growth is equally important in the Shanghainese children as it is with their Swedish counterparts. This study also identified two new predictors for the age at onset of the childhood phase of growth, i.e. height before onset and mid-parental height. Another interesting finding was the distinct BMI pattern in the Chinese population between birth and $6 \mathrm{y}$ of age in comparison with white values.

\section{REFERENCES}

1. Karlberg J 1987 On the modeling of human growth. Stat Med 6:185-192

2. Karlberg J, Jalil F, Lam B, Low L, Yeung CY 1994 Linear growth retardation in relation to the three phases of growth. Eur J Clin Nutr 48:s25-s43

3. Wang HS, Chard T 1992 The role of insulin-like growth factor-I and insulin-like growth factor-binding protein-1 in the control of human fetal growth. J Endocrinol $132: 11-19$

4. Leger J, Oury JF, Noel M, Baron S, Benali K, Blot P, Czernichow P 1996 Growth factors and intrauterine growth retardation. I. Serum growth hormone, insulin-like growth factor IGF-I, IGF-II, and IGF binding protein 3 levels in normally grown and growth-retarded human fetuses during the second half of gestation. Pediatr Res 40:94-100

5. Karlberg J, Albertsson-Wikland K 1988 Infancy growth pattern related to growth hormone deficiency. Acta Paediatr Scand 77:385-391

6. Wit JM, van-Unen H 1992 Growth of infants with neonatal growth hormone deficiency. Arch Dis Child 67:920-924

7. Karlberg J, Engstrom I, Karlberg P, Fryer JG 1987 Analysis of linear growth using a mathematical model. I. From birth to three years. Acta Paediatr Scand 76:478-488

8. Liu YX, Albertsson-Wikland K, Karlberg J 2000 New reference for the age at childhood onset of growth and secular trend in the timing of puberty in Swedish. Acta Paediatr, 89:637-643

9. Liu YX, Jalil F, Karlberg J 1998 Growth faltering in early life in relation to the onset of the childhood component of growth. J Pediatr Endocrinol Metab 11:247-260

10. Liu YX, Albertsson-Willand K, Karlberg J 2000 Long-term consequences of early linear growth retardation (stunting) in Swedish children. Pediatr Res 47:475-480

11. Low LC, Tam SY, Kwan EY, Tsang AM, Karlberg J 2001 Onset of significant $6 \mathrm{H}$ dependence of serum I6F-I and I6F-I binding protein 3 concentrations in early life. Pediatr Res 50:737-742

12. Karlberg J, Kjellmer I, Kristiansson B 1991 Linear growth in children with cystic fibrosis. I. Birth to 8 years of age. Acta Paediatr Scand 80:508-514

13. He Q, Albertsson K, Karlberg J 2000 Population-based body mass index reference values from Goteborg, Sweden: birth to 18 years of age. Acta Paediatr 89:582-592

14. Luo ZC 2000 Intrinsic and extrinsic influences on final height. Ph.D. Thesis, The University of Hong Kong, Hong Kong SAR

15. SAS Institute, Inc. 1996 SAS Series, Version 6.10. Cary, NC

16. Xu X, Wang WP, Guo ZP 2001 Secular trend in growth between 1980-1996 in Shanghai children. Chin J Child Health Care 9:73-75

17. Davies DP, Leung SS 1985 Growth of Hong Kong infants during the first two years of life. Early Hum Dev 11:247-254

18. Victora CG, Gigante DP, Barros AJ, Monteiro CA, de Onis M 1998 Estimating the prevalence of height for age deficits based on the prevalence of weight for age deficits among Brazilian children. Rev Saude Publica 32:321-327

19. Gregory JW, Greene SA, Jung RT, Scrimgeour CM, Rennie MJ 1993 Metabolic effects of growth hormone treatment: an early predictor of growth response? Arch Dis Child 68:205-209

20. Leger J, Garel C, Fjellestad-Paulsen A, Hassan M, Czernichow P 1998 Human growth hormone treatment of short-stature children born small for gestational age: effect on muscle and adipose tissue mass during a 3-year treatment period and after 1 year's withdrawal. J Clin Endocrinol Metab 83:3512-3516

21. He Q, Ding ZY, Fong DYT, Karlberg J 2000 Risk factors of obesity in preschool children in China: a population-based case-control study. Int J Obes Relat Metab Disord, 24:1528-1536 
22. Hammer LD, Kraemer HC, Wilson DM, Ritter PL, Dornbusch SM 1992 Standardized percentile curves of body mass index for children and adolescents. Am J Dis Child 145:259-263

23. Tam SYM, Karlberg JPE, Kwan EYW, Tsang AMC, Sheng HP, He Q, Low LCK 1999 Body mass index is different in normal Chinese and Caucasian infants. J Pediatr Endocrinol Metab 12:507-517

24. Barker DJP, Gluckman PD, Godfrey KM, Harding JE, Owens JA, Robinson JS 1993 Fetal nutrition and cardiovascular disease in adult life. Lancet 341:938-941
25. Cheung YB, Low Louis, Osmond C, Barker D, Karlberg J 2000 Fetal growth and early postnatal growth are related to blood pressure in adults. Hypertension, 36:795-800

26. Geleijnse JM, Hofman A, Witteman JC, Hazebroek AA, Valk-enburg HA, Grobbee DE 1997 Long-term effects of neonatal sodium restriction on blood pressure. Hypertension 29:913-917

27. Hu FB, Wang B, Chen C, Jin Y, Yang J, Stampfer MJ, Xu X 2000 Body mass index and cardiovascular risk factors in a rural Chinese population. Am J Epidemiol 151:88-97 